\title{
Validation of an analytical method for the determination of ascorbic acid and nicotinic acid in fresh meat preparations by HPLC-UV-DAD
}

\author{
Marco Iammarino, Aurelia Di Taranto \\ Struttura Complessa “Chimica” - Istituto Zooprofilattico Sperimentale Della Puglia e Della Basilicata, Via Manfredonia 20, 71121 Foggia, \\ Italy
}

\section{Email address:}

marco.iammarino@tin.it (M. Iammarino)

\section{To cite this article:}

Marco Iammarino, Aurelia Di Taranto. Validation of an Analytical Method for the Determination of Ascorbic Acid and Nicotinic Acid in Fresh Meat Preparations by HPLC-UV-DAD. Journal of Food and Nutrition Sciences. Special Issue: Emerging Issues in Food Safety, Food Additives: Risk Assessment, Analytical Methods and Replacement in Foodstuffs. Vol. 3, No. 1-1, 2015, pp. 7-12.

doi: $10.11648 /$ j.jfns.s.2015030101.12

\begin{abstract}
Fresh meat preparations, as fresh sausages, hamburger, minced meats etc, are susceptible to rapid oxidation and the consequent browning of meat red color compromises the product attractiveness. As a result for the producers, there is the drastic reduction of products shelf-life. In order to remedy such economic loss, the addition of some substances with antioxidant effect may represent a valid solution. However, the addition of some food antioxidants (i.e. nicotinic acid, sulphiting agents, etc.) is not admitted in fresh meat preparations by the actual Normative; moreover, for other substances, such as ascorbic acid, some use restriction subsist. In this work, an analytical method for the determination of two food antioxidants, such as ascorbic acid and nicotinic acid, in fresh meat preparations, by high performances liquid chromatography coupled with UV Diode Array Detection, is described. The reliability of this method was assured by developing a full validation procedure, by following the actual European Guidelines. The most important validation parameters, such as linearity, specificity, accuracy, detection and quantification limits, ruggedness and measurement uncertainty were evaluated, resulting conform with European requirements. Considering that ascorbic acid and nicotinic acid are subject to use restriction in fresh meat preparations, this method may be considered a valid tool in food inspection for organisms in charge of food controls.
\end{abstract}

Keywords: Ascorbic acid, Nicotinic acid, Food antioxidants, Fresh meat Preparations, liquid chromatography, validation

\section{Introduction}

Fresh meat preparations, such as fresh sausages, hamburger, minced meats etc. are susceptible to a rapid oxidation and the consequent meat browning compromises the attractiveness of these products.

In order to remedy such economic loss, the addition of some substances with antioxidant effect may represent a valid solution. However, the addition of some food antioxidants (i.e. nicotinic acid, sulphiting agents, etc.) is not admitted in fresh meat preparations by the actual Normative; moreover, for other substances, such as ascorbic acid, some use restriction subsist [1] [2].

It is important to underline that fresh meats represent an ideal substratum for microorganisms growth (both spoilage and pathogens), so, such sophistication may become a potential risk for consumers, turning a commercial fraud in a food safety problem.

The food additives used for this type of food sophistication (Tab.1) are ascorbic acid and ascorbates, nicotinic acid and sulphiting agents.

Nicotinic acid and sulphiting agents are not admitted in fresh meat preparations; only ascorbic acid (other than citric acid/citrates, lactates and acetates) is admitted as food antioxidant in this type of food product. Nevertheless, it is possible to add this food additive only in "pre-packed" fresh meat preparations after a regular authorization related to food products packaging [3]. Unfortunately, such limitation is often neglected, probably because information about these legislative aspects is lacking. Consequently, in fresh meat preparation samples withdrawn from producers unprovided of the necessary authorizations, it is possible to find ascorbic acid levels up to grams for kilo [4] [5]. 
Table 1. Food additives used as antioxidants in fresh meat preparations

\begin{tabular}{ll}
\hline Food Additive & European Code \\
\hline Sulphur dioxide & E220 \\
Sodium sulfite & E221 \\
Sodium bisulfite & E222 \\
Sodium metabisulfite & E223 \\
Potassium metabisulfite & E224 \\
Calcium sulfite & E226 \\
Calcium bisulfite & E227 \\
Potassium bisulfite & E228 \\
Ascorbic acid & E300 \\
Sodium ascorbate & E301 \\
Calcium ascorbate & E302 \\
Nicotinic acid & N. A. \\
\hline
\end{tabular}

All told, the Organisms in charge of official controls of food products have to develop appropriate control plans in order to verify the absence of not admitted food antioxidants in fresh meat preparations. These activities may foresee the analyses of an elevated number of samples; therefore, the laboratories need techniques that have to be more than precise and reliable, as far as possible, also rapid and economic.

Actually, the analytical determinations of ascorbic acid and nicotinic acid are usually performed by employing enzymatic kits and spectrophotometric quantifications; however, these techniques are characterized by low specificity (cross-reactivity problems) high costs, and, consequently, they are used only for "screening" purposes.

In this work, an analytical method by high performances liquid chromatography, coupled with UV-Diode Array Detection, for the determination of ascorbic acid and nicotinic acid (Fig. 1) in fresh meat preparations, is proposed. The related validation procedure is also described.<smiles>O=C1O[C@H]([C@H](O)CO)C(O)=C1O</smiles>

ASCORBIC ACID<smiles>O=C(O)c1cccnc1</smiles>

NICOTINIC ACID

\section{Materials and Methods}

L-Ascorbic acid ( $\geq 99.0 \%)$, nicotinic acid $(\geq 98.0 \%)$ and sodium acetate anhydrous were supplied by Sigma-Aldrich (Stenheim, Germany); phosphoric acid (85.0\%), acetic acid glacial, sodium hydroxide $(50 \% \mathrm{w} / \mathrm{v})$ and acetonitrile of HPLC grade were purchased from J.T. Baker (Deventer, Netherlands); potassium phosphate monobasic $(\geq 98.0 \%)$ and potassium phosphate bibasic $(\geq 98.0 \%)$ were supplied by Carlo Erba Reagenti (Milan, Italy). All solutions were prepared in ultrapure water with a specific resistance of $18.2 \mathrm{M} \Omega-\mathrm{cm}$, supplied by a Milli-Q RG unit, Millipore (Bedford, MA, USA). The phosphate buffer used for sample extraction was obtained dissolving $1.36 \mathrm{~g}$ of potassium phosphate monobasic and $1.74 \mathrm{~g}$ of potassium phosphate bibasic in $1000 \mathrm{~mL}$ of ultrapure water and then correcting the $\mathrm{pH}$ value to 3.5 and to 9.0 by addition of phosphoric acid and sodium hydroxide respectively.

The chromatographic method for the determination of ascorbic acid and nicotinic acid in fresh meat preparations was developed by modifying a protocol proposed by Phenomenex (Torrance, CA) [6]. This method employs the Reversed Phase Liquid Chromatography coupled with UV-Diode Array Detection (UV-DAD) [7] [8]. The chromatographic separations were performed by using a HPLC system Waters ${ }^{\mathrm{TM}} 2690$ Separations Module (Milford, MA) equipped with a Waters ${ }^{\mathrm{TM}} 996$ PDA Detector (Milford, MA), a micro vacuum degasser, an autosampler and a column compartment. The chromatographic column was a Luna C18 column $(250 \times 4.6 \mathrm{~mm}$ i.d., particle size $5 \mu \mathrm{m}$. Phenomenex, Torrance, CA) equipped with a HILIC Security Guard Cartridge $(4 \times 3.0$ $\mathrm{mm}$. Phenomenex, Torrance, CA). A gradient elution of acetonitrile, water and acetate buffer $100 \mathrm{mM}, \mathrm{pH} 5.8$, at a flow-rate of $1.5 \mathrm{~mL} \mathrm{~min}^{-1}$ was optimised in order to obtain both a suitable separation of analytes from interfering compounds and good peaks symmetry. The gradient elution is described in table 2 .

Figure 1. Compounds analysed in this study

Table 2. Gradient elution

\begin{tabular}{ll}
\hline Time (minutes) & \%A (Acetonitrile) \\
\hline 0.0 & 90 \\
2.5 & 90 \\
7.5 & 50 \\
10.0 & 50 \\
11.0 & 90 \\
15.0 & 90 \\
\hline
\end{tabular}

The extraction of analytes form samples was obtained by using two buffers characterised by different $\mathrm{pH}$ values. Indeed, ascorbic acid and nicotinic acid show a pH-dependent stability. Ascorbic acid is stable at acid $\mathrm{pH}$, so it was treated with a $10^{-2}$ $\mathrm{M}$ phosphate buffer, $\mathrm{pH} 3.5$; while nicotinic acid, which is unstable at acid $\mathrm{pH}$, was treated with a $10^{-2} \mathrm{M}$ phosphate buffer, $\mathrm{pH} 9.0$.

4 grams of sample, homogenized by a blade homogenizer,

\begin{tabular}{ll} 
\%B (Water) & \%C (Acetate buffer) \\
\hline 5 & 5 \\
5 & 5 \\
45 & 5 \\
45 & 5 \\
5 & 5 \\
5 & 5 \\
\hline
\end{tabular}

were placed in a $50 \mathrm{~mL}$ plastic tube and $40 \mathrm{~mL}$ of specific buffer were added. The sample was vortexed for 1 minute and then centrifuged at $250 \mathrm{xg}$ for $5 \mathrm{~min}$ (room temperature). The supernatant was filtered by using Whatman No. 40 filters (Whatman, Springfield Mill, UK) and then $\sim 1.5 \mathrm{~mL}$ of filtrate were filtered again by using Anotop $10 \mathrm{LC}$ filters $(0.2$ $\mu \mathrm{m}, 10 \mathrm{~mm}$, Whatman, Springfield Mill, UK) directly in vial for chromatographic analysis. The purified sample may be injected within 4 hours (if stored under refrigeration). 
The signal was acquired at a wavelength of $260 \mathrm{~nm}$; moreover, the absorbance spectrum in the wavelength range corresponding to $200-400 \mathrm{~nm}$ was acquired in order to improve notably the method selectivity (Fig. 2).
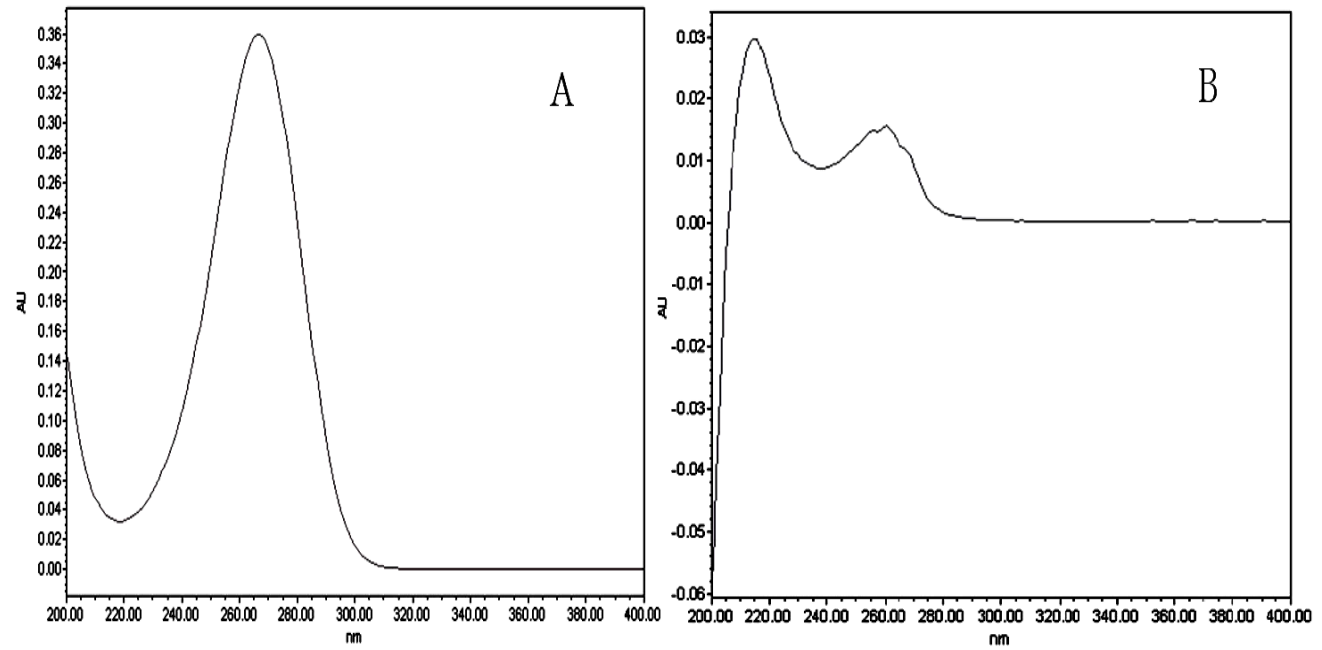

Figure 2. Absorbance spectrum of ascorbic acid (A) and nicotinic acid (B)
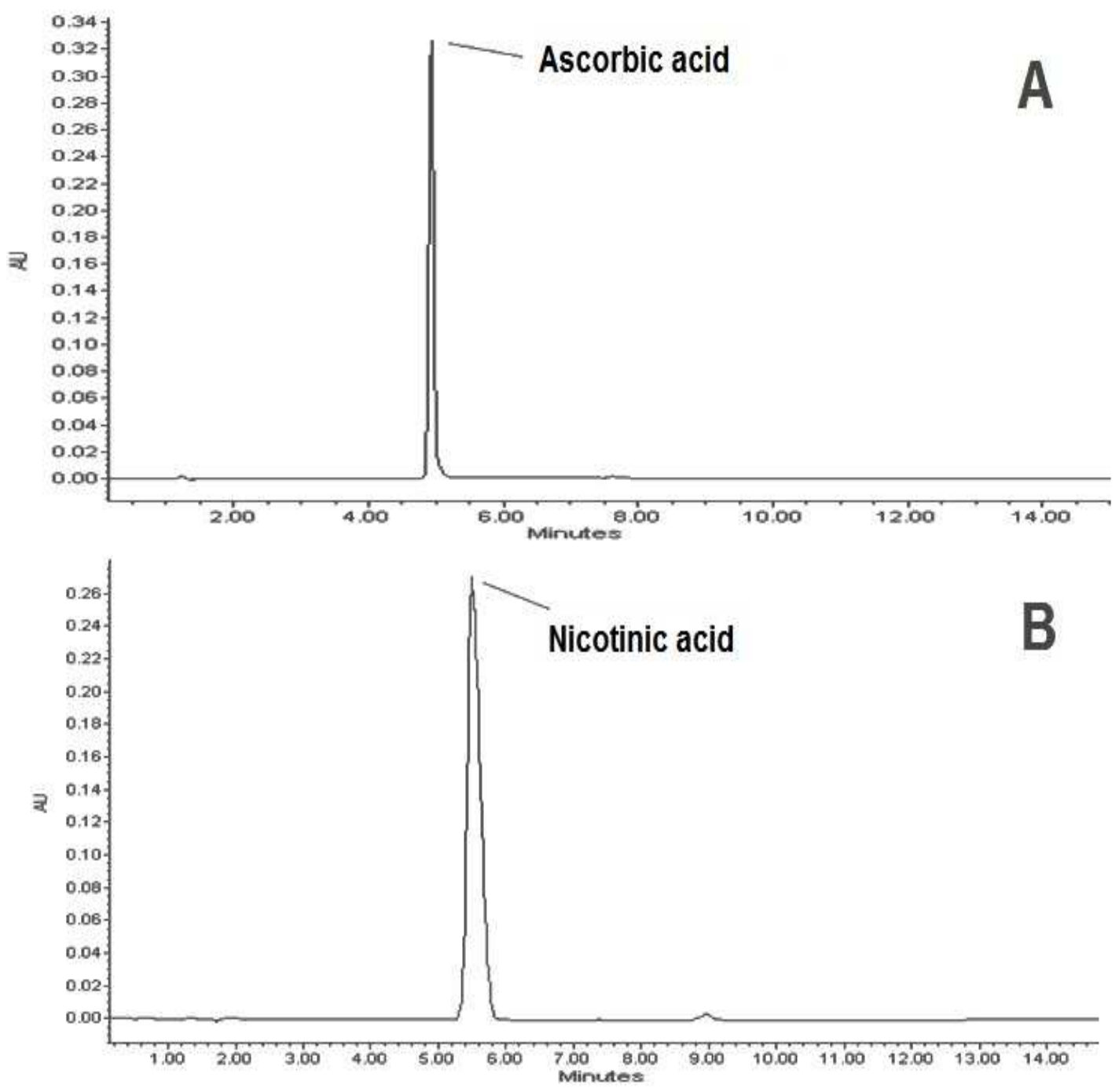

Figure 3. Chromatograms of standard solutions: Ascorbic acid $50 \mathrm{mg} \mathrm{kg}^{-1}$ (A); Nicotinic acid $25 \mathrm{mg} \mathrm{kg}^{-1}$ (B) 

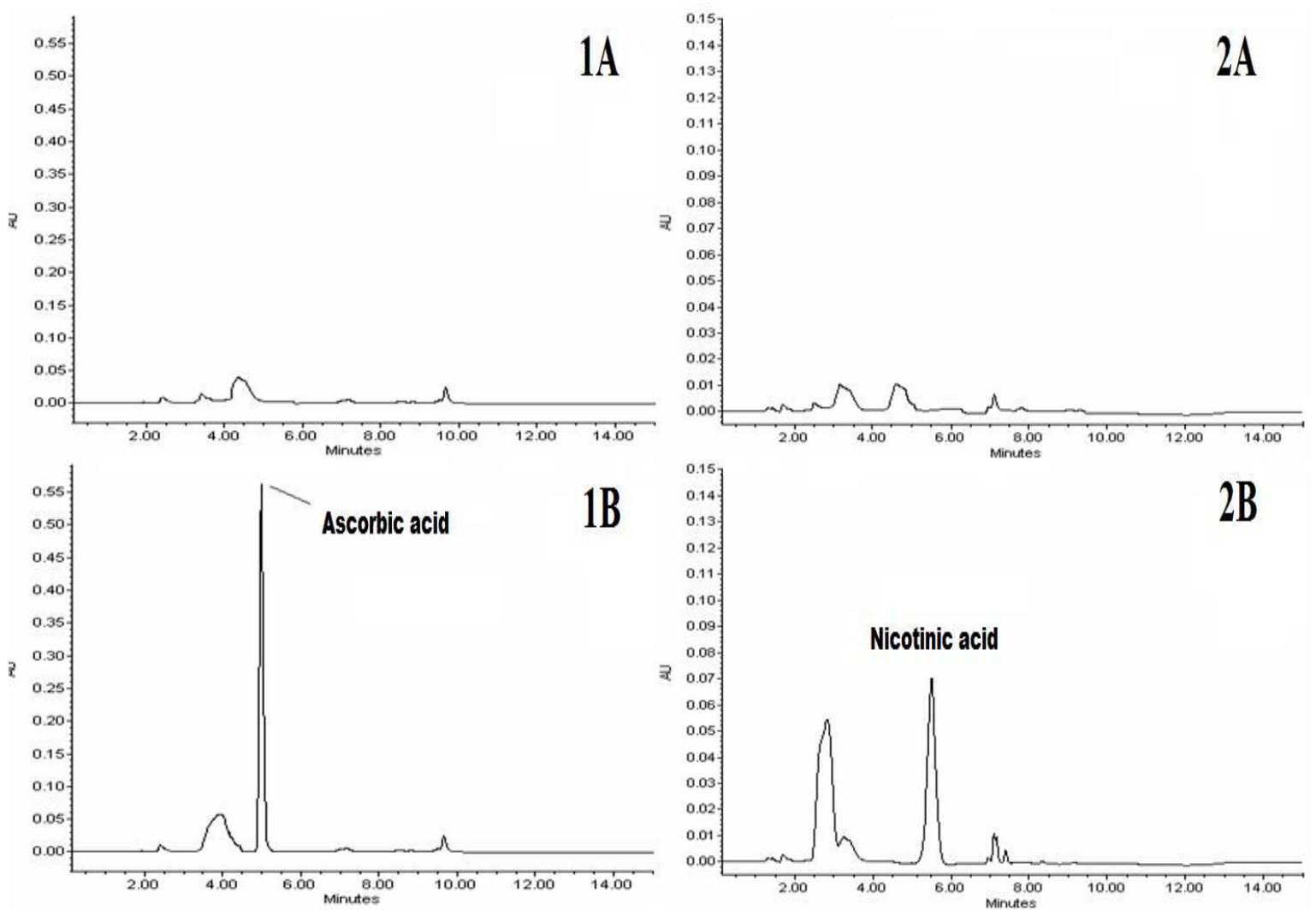

Figure 4. Comparison blank/spiked samples: Cow fresh sausage samples with no ascorbic acid residue (1A) and with an ascorbic acid concentration equal to $693.3 \mathrm{mg} \mathrm{kg}^{-1}(1 \mathrm{~B})$; Pork fresh sausage samples with no nicotinic acid residue (2A) and spiked with nicotinic acid at a concentration equal to $50 \mathrm{mg} \mathrm{kg}^{-1}$ (2B)

\section{Results and Discussion}

The described analytical method, optimized for the determination of ascorbic acid and nicotinic in fresh meat preparations, was submitted to a validation procedure, by following an in-house approach which made reference to the most important Guidelines and European Regulations [9 - 11] The most important validation parameters, obtained in this study, are reported in table 3 . Through the validation procedure, the following analytical parameters were evaluated:

Linearity. The analysis of this parameter was carried out by analysing thrice, five standard solutions at ascorbic acid and nicotinc acid concentrations equal to $12.5,25,50,100$ and $200 \mathrm{mg} \mathrm{L}^{-1}$. The values related to determination coefficient $\left(r^{2}>0.990\right)$, intercept and slope were evaluated for each curve and for the mean curve. Through this validation step the instrumental linearity was verified and the measurement range was determined, resulting equal to 20.1 (LOQ) - $2000 \mathrm{mg} \mathrm{kg}^{-1}$ and 20.4 (LOQ) - $2000 \mathrm{mg} \mathrm{kg}^{-1}$ for ascorbic acid and nicotinic acid, respectively. In Figure 3, two chromatograms, related to an ascorbic acid and a nicotinic acid standard solution, are shown.

Specificity. This parameter was ascertained by analyzing 20 samples of fresh meat preparations ( 5 cow, 5 pork, 5 equine and 5 chicken) and verifying the absence of interfering peaks within the "integration window", which corresponds to the range: ascorbic acid and nicotinic acid retention times $+/-2.5 \%$. This characteristic was confirmed for all types of analysed samples, confirming method specificity and, at the same time, a good "robustness" under this point of view, since different meat types were considered for this study. In Figure 4 two chromatograms related to "blank" samples are shown.

Detection limits. The values of limits of determination (LOD) and of quantification (LOQ) were elaborated by using the parameters of calibration curves of ascorbic acid and nicotinic acid. The approach adopted in this study was those described by Miller \& Miller [12]: $\mathrm{LOD}=3.3 \mathrm{~s}_{\mathrm{a}} / \mathrm{b}$ and $\mathrm{LOQ}=$ $10 s_{a} / b$, where $s_{a}$ is the standard deviation of the intercept and $\mathrm{b}$ is the slope of the regression line obtained from the calibration curve. LOD and LOQ values of $6.6 \mathrm{mg} \mathrm{kg}^{-1}$ and $20.1 \mathrm{mg} \mathrm{kg}^{-1}$ in matrix, respectively, were obtained for ascorbic acid, whereas these values corresponded to $6.7 \mathrm{mg}$ $\mathrm{kg}^{-1}$ and $20.4 \mathrm{mg} \mathrm{kg}^{-1}$ in matrix, respectively, for nicotinic acid.

Accuracy. This parameter was evaluated in terms of precision (as $\mathrm{CV} \%$ ) and trueness (as recovery\%). Actually, certified materials related to this type of determination are not available; consequently, these parameters were evaluated by analyzing samples spiked with known analytes concentrations. In particular the tests were carried out under conditions of "intermediate precision" that consists in the analysis of three sets of six samples each (cow fresh meat samples), spiked at three fortification levels, equal to 50,500 and $1000 \mathrm{mg} \mathrm{kg}^{-1}$ both for ascorbic acid and nicotinic acid. 
The most significant results are reported in table 3 . Briefly, the precision, assessed as $\mathrm{CV} \%$, resulted $<5.3 \%$ and $<1.8 \%$ for ascorbic acid and nicotinic acid, respectively. The recovery \% resulted in the range 97.7-114.0 for ascorbic acid and 97.2-104.1 for nicotinic acid. The values obtained for these two parameters were comparable with those suggested by the actual Normative [10] [11] assuring method accuracy. In Figure 4 two chromatograms related to spiked samples are shown.

Ruggedness. Method ruggedness was evaluated under major changes conditions (different matrices to analyse) by using the Youden factorial experimental design [13]. For this test, 12 independent experiments (four with validation matrix (cow fresh meat) and four with each alternative matrix (4 pork, 4 horse and 4 chicken)) were carried out. The samples were spiked at a level corresponding to $500 \mathrm{mg} \mathrm{kg}^{-1}$ of ascorbic acid and nicotinic acid. The seven factors chosen as variables for the Youden test were the matrix and six fictitious factors; the use of a fictitious variable means no variation in analysis conditions. Analysis of each alternative matrix gave a value of standard deviation of difference lower than the estimated method precision $(\mathrm{CV} \%)$ of the method (table 3). These results confirmed that the matrix variation has no effect on the analytical performances and, consequently, the method is also applicable to pork, horse and chicken fresh meat preparations.

Measurement uncertainty. The evaluation of this parameter is compulsory for laboratories accredited according to ISO 17025 [14] and several methods for its determination were proposed [15]. In this study, the bottom-up method was used for this evaluation, as proposed in the ISO Guide 98:1993 [16], through the appropriate combination of the following uncertainty factors, elaborated during validation: (1) repeatability; (2) recovery \%; (3) weights (4) volume measurements; (5) reference materials; (6) instrumental calibration [17]. The values of measurement uncertainty resulted equal to $5.6 \%$ and $4.5 \%$ for ascorbic acid and nicotinic acid, respectively.

Table 3. Validation parameters

\begin{tabular}{lll}
\hline Validation Parameter & Ascorbic acid & Nicotinic acid \\
\hline $\begin{array}{l}\text { Specificity } \\
\text { Linearity }\left(r^{2}\right)\end{array}$ & No Interferences & No Interferences \\
$\begin{array}{l}\text { Limit of Detection } \\
\text { (LOD in matrix) }\end{array}$ & 0.9997 & 0.9999 \\
Limit of Quantification & $6.6 \mathrm{mg} \mathrm{kg}^{-1}$ & $6.7 \mathrm{mg} \mathrm{kg}^{-1}$ \\
(LOQ in matrix) & $20.1 \mathrm{mg} \mathrm{kg}^{-1}$ & $20.4 \mathrm{mg} \mathrm{kg}^{-1}$ \\
Precision (CV\%) (range) & $3.8-5.3$ & $0.4-1.8$ \\
Recovery\% (range) & $97.7-114.0$ & $97.2-104.1$ \\
& Cow, pork, equine & Cow, pork, equine \\
Ruggedness & and chicken fresh & and chicken fresh \\
& meats & meats \\
Measurement uncertainty & $5.6 \%$ & $4.5 \%$ \\
\hline
\end{tabular}

\section{Conclusion}

In the present work, an analytical method for the determination of ascorbic acid and nicotinic acid in fresh meat preparations, by high performances liquid chromatography, coupled with UV Diode Array Detection, is described. The optimized method, which requires a minimal sample pre-treatment, represents an improvement in the determination of these two compounds in food products, and it can be considered faster than the official techniques typically used in control laboratories; in fact, it is possible to analyse up to 20 real samples in an 8 -h-work-day. The validation procedure allowed to verify the most important analytical performances, by assuring method reliability and applicability for routinely controls. In particular:

1) The limits of determination (LOD and LOQ) allow quantitative determinations at levels well lower than usual concentrations employed in food processing;

2) The values related to precision $(\mathrm{CV} \%)$ are lower than reference values, calculated by Horwitz equation (Dec. 657/2002/EC). This assures an appropriate method repeatability;

3) The values related to recovery $\%$ and measurement uncertainty, combined to ruggedness and specificity tests, make the analytical method fully suitable for the determination of ascorbic acid and nicotinic acid in cow, pork, horse and chicken fresh meat preparations.

\section{Acknowledgements}

The Ministero della Salute (Rome, Italy) is thanked for financial support.

\section{References}

[1] Paturzo F., Bizzozero N. Risultati di un'indagine sul contenuto di additivi in campioni commerciali di carne trita. Ingegneria Alimentare, 3, 15-16, 2001.

[2] Bizzozero N., Nidasio S., Sprocati G. Analisi del contenuto di acido nicotinico e di nicotinammide in campioni commerciali di insaccati. Ingegneria Alimentare, 1, 9-12, 2001.

[3] European Commission. Commission Regulation (EU) No. 1129/2011 of 11 November 2011 amending Annex II to Regulation (EC) No 1333/2008 of the European Parliament and of the Council by establishing a Union list of food additives. Journal of the European Union, L295, 1-177, 2011.

[4] Iammarino M., Di Taranto A. Monitoring on the presence of ascorbic acid in not prepacked fresh meat preparations by a validated HPLC method. Journal of Food Research, 1(2), 22-31, 2012.

[5] Iammarino M., Di Taranto A. Evaluation of Natural Levels of Substances Commonly-Used as Food Additives in Fresh Meat Preparations. In: Ortega M.P. and Soto R. Eds., Meat Consumption and Health - Food and Beverage Consumption and Health. Nova Science Publisher, Hauppauge NY, USA, 153-170, 2013.

[6] Phenomenex, Inc. Chromatography Product Guide 11/12. Vitamin Mix on Luna HILIC, p. 207, 2011.

[7] Iammarino M., Di Taranto A., Muscarella M. Investigation on the natural presence of substances with preservative effects in minced meat preparations. Ingredienti Alimentari, 15-23, 2011. 
[8] Iammarino M., Di Taranto A. Preparazioni carni fresche: HPLC per la determinazione di sostanze antiossidanti non ammesse. Laboratorio 2000, 44-50, 2011.

[9] Thompson M., Ellison, S.R.L., Wood R. Harmonized guidelines for single laboratory validation of methods of analysis. Pure Appl Chem, 74(5), 835-855, 2002.

[10] European Commission. Commission Decision 2002/657/EC of 12 August 2002 implementing Council Directive 96/23/EC concerning the performance of analytical methods and the interpretation of results. Official Journal of the European Union, 17 August 2002, L221, 8-36, 2002.

[11] European Commission. Regulation (EC) No 882/2004 of the European Parliament and of the Council of 29 April 2004 on official controls performed to ensure the verification of compliance with feed and food law, animal health and animal welfare rules. Official Journal of the European Union, 30 April 2004, L165, 1-141, 2004.

[12] Miller E.J.C., Miller J.N. Statistics for Analytical Chemistry. $3^{\text {rd }}$ ed. New York (USA): Ellis Horwood PTR Prentice Hall, p.115, 1993.
[13] Youden W.J., Steiner E.H. Statistical manual of the AOAC. Washington (DC): Association of the Official Analytical Chemists, p. 35, 1975.

[14] [ISO] International Organization for Standardization. UNI CEI EN ISO/IEC 170252000 - General requirements for the competence of testing and calibration laboratories. Geneva: ISO Central Secretariat, 2000.

[15] EURACHEM/CITAC. CITAC Guide number 4. In: Ellison S.L.R., Rosslein M., Williams A., editors. Quantifying uncertainty in analytical measurement, $2^{\text {nd }}$ ed. EURACHEM/CITAC Working Group, 2000.

[16] [ISO] International Organization for Standardization. Guide to the expression of uncertainty in measurement (GUM). Geneva: ISO Central Secretariat, 1993.

[17] Hund E., Massart D.L., Smeyers-Verbeke J. Operational definitions of uncertainty. TrAC, Trends Anal Chem, 20, 394-406, 2001. 